\title{
Heat shock protein 90 is downregulated in calcific aortic valve disease
}

\author{
Jonna Weisell ${ }^{1}$, Pauli Ohukainen ${ }^{2}$, Juha Näpänkangas ${ }^{3}$, Steffen Ohlmeier ${ }^{4}$, Ulrich Bergmann ${ }^{4}$, Tuomas Peltonen ${ }^{5}$, \\ Panu Taskinen ${ }^{6,7}$, Heikki Ruskoaho ${ }^{5,8}$ and Jaana Rysä ${ }^{1,5^{*}}$ (1)
}

\begin{abstract}
Background: Calcific aortic valve disease (CAVD) is an atheroinflammatory process; finally it leads to progressive calcification of the valve. There is no effective pharmacological treatment for CAVD and many of the underlying molecular mechanisms remain unknown. We conducted a proteomic study to reveal novel factors associated with CAVD.
\end{abstract}

Methods: We compared aortic valves from patients undergoing valvular replacement surgery due to non-calcified aortic insufficiency (control group, $n=5$ ) to a stenotic group $(n=7)$ using two-dimensional difference gel electrophoresis (2D-DIGE). Protein spots were identified with mass spectrometry. Western blot and immunohistochemistry were used to validate the results in a separate patient cohort and Ingenuity Pathway Analysis (IPA) was exploited to predict the regulatory network of CAVD.

Results: We detected an upregulation of complement 9 (C9), serum amyloid P-component (APCS) and transgelin as well as downregulation of heat shock protein (HSP90), protein disulfide isomerase A3 (PDIA3), annexin A2 (ANXA2) and galectin-1 in patients with aortic valve stenosis. The decreased protein expression of HSP90 was confirmed with Western blot.

Conclusions: We describe here a novel data set of proteomic changes associated with CAVD, including downregulation of the pro-inflammatory cytosolic protein, HSP9O.

Keywords: Aortic valve stenosis, Calcified aortic valve disease, Heat-shock protein, Proteomics

\section{Background}

Calcific aortic valve disease (CAVD) is a progressive disease, which originates from endothelial cell damage on the aortic surface of aortic valve followed by an accumulation of oxidized lipids and the infiltration of inflammatory cells into the valve [1]. This promotes active remodeling of the extracellular matrix with the disorganization of collagen fibers, resulting in a thickening of the aortic valve leaflets. Furthermore, osteogenic programming of valve interstitial cells (VICs), causes progressive calcification and ultimately a severe obstruction of cardiac outflow. Several factors and signaling pathways have been linked to CAVD, e.g. interleukins,

\footnotetext{
*Correspondence: jaana.rysa@uef.fi

${ }^{1}$ School of Pharmacy, University of Eastern Finland, POB 1627, 70211 Kuopio, Finland

${ }^{5}$ Department of Pharmacology and Toxicology, University of Oulu, Oulu, Finland

Full list of author information is available at the end of the article
}

tumor necrosis factor (TNF), matrix metalloproteinases, bone morphogenic protein 2 (BMP2) and osteogenic regulator runt-related transcription factor 2 (RUNX2) [1, 2]. However, despite recent progress in understanding the molecular pathogenesis of CAVD, the factors driving the progression of this disease are not fully understood.

Various omics-analyses have been performed to gain a better understanding of the molecular mechanism underpinning CAVD. Transcriptomic studies of human CAVD have been undertaken to identify differentially expressed genes [3-6] and microRNAs [4, 7] in different stages of aortic valve calcification. In addition, there have been multiple proteomics studies of CAVD performed [8-16]. However, only three of them compared stenotic valves to control valves $[9,12,16]$, and of these, only Schlotter et al. [12] reported the use of tricuspid valves in their study. Furthermore, Schlotter et al. [12] combined the results from proteomics and transcriptomics 
to describe the integrated molecular dataset of human CAVD [12].

In this study, we conducted a proteomic analysis of aortic valve calcification by comparing control and stenotic human aortic valves using two-dimensional difference gel electrophoresis (2D-DIGE). Selected proteomic changes were confirmed with Western blotting and immunohistochemistry. In addition, Ingenuity pathway analysis (IPA) was used to clarify the potential signaling pathways associated with identified proteins.

\section{Methods}

\section{Patients}

The aortic valves examined in this study were obtained from 50 patients at the time of aortic valve or aortic root surgery. All operations were made following normal surgical procedures. The study protocol was approved by the Research Ethics Committee of Oulu University Hospital and it conformed to the principles outlined in the Declaration of Helsinki. The aortic valve cusps were immersed immediately after removal into liquid nitrogen and stored at $-70^{\circ} \mathrm{C}$ until analyzed.

For proteomics study, patients were divided into two groups: the control group $(\mathrm{C}, n=5)$ consisted of patients with normal, non-calcified, smooth and pliable aortic valve cusps, operated due to ascending aortic pathology (aneurysm or dissection) or aortic regurgitation. The aortic stenosis group (AS, $n=7$ ) consisted of patients who had non-rheumatic, severe aortic valve sclerosis with an increased degree of calcification. Patients who were identified as exhibiting macroscopic thickenings of aortic valve cusps, which were microscopically identified mainly as fibrotic and mild sclerotic lesions, were excluded from the study.

The patients' demographics are presented in Table 1. There were no significant differences in gender, left ventricular ejection fraction or comorbidities between the study groups, and valve anatomy. However, the average

Table 1 Demographics of the patients examined in the proteomic analysis

\begin{tabular}{llll}
\hline & Control & Aortic Stenosis & $P$-value \\
\hline Patients, n & 5 & 7 & \\
Male, n (\%) & $5(100 \%)$ & $5(71.4 \%)$ & 0.46 \\
Bicuspid valve & 0 & $2(28.6 \%)$ & 0.47 \\
Age (years), range & $43.4(33.2-53.6)$ & $66.6 \pm(53.8-79.3)$ & 0.007 \\
LVEF (SD) & $58.0 \pm 11.2$ & $56.7 \pm 8.8$ & 0.53 \\
DM, n (\%) & 0 & $1(14.3 \%)$ & $\geq 0.9$ \\
CHD, n (\%) & 0 & $3(42.9 \%)$ & 0.21 \\
ASO, n (\%) & 0 & $1(14.3 \%)$ & $\geq 0.9$ \\
Statin use, n (\%) & $1(20 \%)$ & $4(66.7 \%)$ & 0.24 \\
\hline ASO Perpher
\end{tabular}

ASO Peripheral atherosclerosis, CHD Coronary heart disease, DM Diabetes mellitus, LVEF Left ventricle ejection fraction; SD, standard deviation age of the aortic stenosis (AS) patients was significantly higher than the patients in the control group. Histologically, the stenotic valves had a significantly elevated amount of calcium and more neovessels in comparison with control valves $[4,17,18]$. For validation of proteomics results, a separate matching group of patients $(n=$ 39) was selected.

Two-dimensional difference gel electrophoresis (2D-DIGE) The proteins extracted from control $(C, n=5)$ and calcified (AS, $n=7$ ) aortic valves were further purified by buffer exchange using an Amicon Ultra ultrafiltration unit with a $10 \mathrm{kDa}$ cutoff (Millipore) and urea buffer (7 $\mathrm{M}$ urea, $2 \mathrm{M}$ thiourea, $4 \%[\mathrm{w} / \mathrm{v}$ ] CHAPS, $30 \mathrm{mM}$ Tris, $\mathrm{pH}$ 8.5) and then the protein samples were sonicated and centrifuged. Protein amounts in the supernatants were determined with a Bradford-based assay according to the manufacturer's instructions (Roti ${ }^{-}$-Nanoquant) and the aliquots were stored at $-70^{\circ} \mathrm{C}$. Protein labeling was performed with CyDye DIGE Fluor minimal dyes (GE Healthcare) according to the manufacturer's protocol using 400 pmol Cy3 (pooled standard) and Cy5 (control, AS, respectively) for $50 \mu \mathrm{g}$ protein. Proteins were separated as described earlier [19]. In brief, immobilized $\mathrm{pH}$ gradient (IPG) strips (pH 3-10 nonlinear, $24 \mathrm{~cm}, \mathrm{GE}$ Healthcare) were incubated overnight in $650 \mu \mathrm{l}$ rehydration buffer $(7 \mathrm{M}$ urea, $2 \mathrm{M}$ thiourea, $4 \%[\mathrm{w} / \mathrm{v}]$ CHAPS, $130 \mathrm{mM}[\mathrm{w} / \mathrm{v}]$ DTT, 2\%[v/v] carrier ampholytes 3-10, Complete Mini protease inhibitor cocktail [Roche Life Science]). Isoelectric focusing (IEF) after anodic sample cup-loading was carried out with the Multiphor II system (GE Healthcare) under paraffin oil with $67 \mathrm{kVh}$. SDS-PAGE was performed overnight in polyacrylamide gels (12.5\%) with the Ettan DALT II system (GE Healthcare) at $1-2 \mathrm{~W}$ per gel in $12{ }^{\circ} \mathrm{C}$. Fluorescence signals were detected with a Typhoon 9400 (GE Healthcare) and 2-D gels analyzed with Delta2D 4.0 (Decodon). Theoretical spot positions were calculated with the Compute $\mathrm{pI} / \mathrm{Mw}$ tool (http://ca.expasy.org/tools/pi_tool.html). Principal Component Analysis was performed with the Delta2D v4.0 software (Decodon) according to the spot intensities on every gel image.

\section{Mass spectrometry}

For protein identification, additional 2-D gels were run with a higher amount of unlabelled protein $(400-600 \mu \mathrm{g})$ combined with $50 \mu \mathrm{g}$ Cy3-labelled internal standard. After detection of the fluorescence signals (see above) and silver staining, labelled and unlabelled protein patterns were matched with the 2-D PAGE image analysis software Melanie 3.0 (GeneBio). Spots with correctly matched centers were excised, digested with trypsin (recombinant; Roche) and prepared for MALDI-TOF mass spectrometry as described previously [19]. The extracted 
and dried peptides were dissolved in $5 \mu \mathrm{l}$ alpha-Cyano-3hydroxycinnamic acid (98\%, recrystallized from ethanolwater, $5 \mathrm{mg} / \mathrm{ml}$ in $50 \%$ acetonitrile and $0.1 \%$ TFA) and $0.5 \mu \mathrm{l}$ applied onto the sample plate using the drieddroplet method. Proteins were identified from PMF obtained with a VOYAGER-DE ${ }^{\mathrm{m}}$ STR (Applied Biosystems) as described earlier [19]. In general, the clearest peaks (up to 50) visible in the mass spectrum were used to identify proteins with Mascot (http://www. matrixscience.com/) using Swiss-Prot as the corresponding protein database. Search parameters were enzyme: trypsin; modifications: oxidation of Met; missed cleavage: 1; resolution: monoisotopic; ion mode: $[\mathrm{M}+\mathrm{H}]$; threshold: $50 \mathrm{ppm}$. The protein identification was accepted if at least 4 major peaks matched to the protein with the highest Mascot score. In addition, the identification was confirmed by analyzing the induced spot from different gels. During later stages of the project, mass spectra of the tryptic digests were obtained with a UltrafleXtreme MALDI TOF/TOF instrument (Bruker Daltonics) where up to 10 ions from each peptide fingerprint were subjected to the MS/MS measurement. Data were processed with Flexanalyis and Biotools (Bruker) and combined PMF/MS/MS spectra were searched against the NCBI or Swiss-Prot non-redundant protein database using Mascot (Matrix science) with standard search parameters (MS tolerance: $30 \mathrm{ppm}, \mathrm{MS} / \mathrm{MS}$ tolerance: $0.7 \mathrm{Da}$, modifications: Carbamidomethyl (Cys) and optional oxidation of Met, up to 1 missed cleavage).

\section{Protein extraction and Western blot}

In the western blot experiments, aortic valve samples were obtained from a separate matching cohort $(C, n=$ 19 AS, $n=20$ ). The samples were ground in liquid nitrogen, and then homogenized for $10 \mathrm{~min}$ in a lysis buffer containing inhibitors. The lysis buffer itself contained 1 $M$ Tris (pH 7.5), $3 \mathrm{M} \mathrm{NaCl}, 0.25 \mathrm{M}$ EDTA (pH 8.0), 0.1 M EGTA (pH 7.9), $1 \mathrm{mmol} / \mathrm{l} \quad \beta$-glycerophosphate, 1 $\mathrm{mmol} / \mathrm{l} \mathrm{Na} 3 \mathrm{VO} 4,2 \mathrm{mmol} / \mathrm{l}$ benzamidine, $1 \mathrm{mmol} / \mathrm{l}$ phenylmethylsulfoxide, $50 \mathrm{mmol} / \mathrm{l} \mathrm{NaF}, 1 \mathrm{mmol} / \mathrm{l}$ dithiothreitol and $10 \mu \mathrm{g} / \mathrm{ml}$ each of leupeptin, pepstatin, aprotininand and distilled water. The valve tissue samples were homogenized using a MagnaLyser instrument (Roche). After homogenization, the samples were centrifuged for $20 \mathrm{~min}$ in $12,500 \mathrm{rpm}$ and $+4{ }^{\circ} \mathrm{C}$ and then the supernatant was collected for protein isolation. $5 \mathrm{x}$ NEB lysis buffer (100 mM Tris- $\mathrm{HCl}$ [pH 7.5], $750 \mathrm{mM}$.

$\mathrm{NaCl}, 5 \mathrm{mM}$ EDTA, $5 \mathrm{mM}$ EGTA, $5 \%$ Triton X 100, $12 \mathrm{mM}$ sodium pyrophosphate, $5 \mathrm{mM} \quad \beta$ glycerophosphate, $5 \mathrm{mM} \mathrm{Na}_{3} \mathrm{VO}_{4}$ ) was added and mixed following centrifugation for $20 \mathrm{~min}$ in $12,500 \mathrm{rpm}$ in + $4{ }^{\circ} \mathrm{C}$. Supernatant containing the total fraction was collected. Western blot was performed using a $1.0 \mathrm{~mm}, 12 \%$ gel with $40 \mu \mathrm{g}$ of protein/well. The following primary antibodies were used: HSP90 $\alpha$ (ADI-SPS-771) and HSP90 $\beta$ (ADI-SPA-844) from Enzo Life Sciences, Protein kinase B (Akt) (\#9272), Phospho- Akt (\#4056), p38 mitogen activated protein kinase (MAPK) (\#9212), phospho-p38 MAPK (\#9211), extracellular signal regulated kinase p44/42 MAPK (Erk1/2) (\#9102) and Phospho-p44/42 MAPK (pErk1/2) (\#9106) from Cell Signaling Technology, Inc., Anti-Annexin II $(610,068$, BD Transduction Laboratories), and Anti-Galectin 1 (ab25138, Abcam). Anti-mouse-IgG HRP-labeled (GE Healthcare), Anti-rabbit-IgG Peroxidase conjugate (Calbiochem), anti-IgG HRP-linked rabbit (\#7074, Cell Signaling Technology, Inc.), and anti-IgG HRP-linked mouse (\#7076, Cell Signaling Technology, Inc.) secondary antibodies were used. Data was quantified using the QuantityOne Software (Bio-Rad).

\section{Histological stainings}

The localization of HSP90 $\alpha$ and HSP90 $\beta$ in the aortic valve cusps was studied by using immunohistochemical stainings. The aortic valve samples, sent for routine diagnistics, were fixed in buffered formalin solution and embedded in paraffin. Decalcification with EDTA was done if needed. For total valve area and calcified valve area slides were photographed with a Leica DFC420 camera (Wetzlar) and areas were quantified with Image $J$ analysis software. Calcified area to total area was calculated with the following formula: (calcified valve area/ total valve area)*100. Before application of the primary antibodies, the 5$\mu \mathrm{m}$-thick sections of valves samples were heated in a microwave oven in citrate buffer, $\mathrm{pH} 6.0$, for $30 \mathrm{~min}$. Rabbit monoclonal antibodies ab133492 at a dilution of 1:2000 (Abcam) for HSP90 $\alpha$ and ab32568 at a dilution of 1:300 (Abcam) for HSP90 $\beta$ were used to stain. 3,3' Diaminobenzidine (DAP) was used as the chromogen in immunostaining process. Negative control stainings were carried out by substituting nonimmune rabbit serum for the primary antibodies.

\section{Molecular network analysis}

The up- or down-regulated proteins with their respective expression values were uploaded for processing by the Ingenuity Pathway Analysis (IPA) software (Qiagen). A core analysis was performed with the following parameters: core analysis, reference set userdefined (i.e., only the set of differentially expressed genes by GeneSpring-software mapped to the IPA database), direct and indirect relationships included, confidence $=$ experimentally observed. Then, the IPAsoftware was used to generate a molecular network showing the interrelationships between up- or downregulated proteins as previously described [20], based 


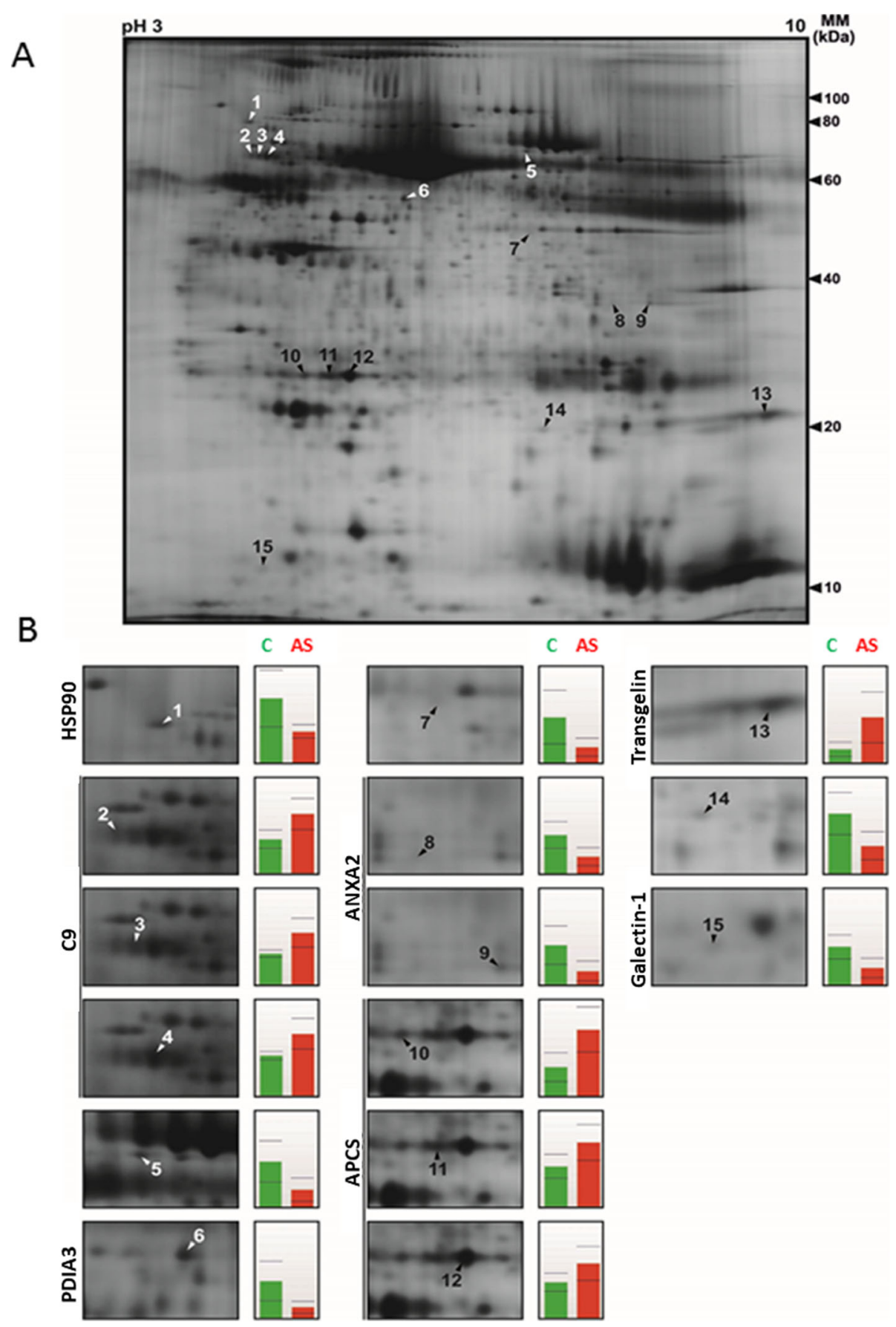

Fig. 1 CAVD-related proteomic changes in human aortic valves. a Representative 2-D gel of calcified aortic valve is shown. Proteins (50 $\mu \mathrm{g})$ were labelled with minimal DIGE and separated by IEF ( $\mathrm{pH} 3-10 \mathrm{NL}$ ) and SDS-PAGE. $\mathbf{b}$ The positions of the changed spots as well as the expression profiles indicating the detected protein levels in control (C) and stenotic (AS) aortic valves are specified. HSP90, heat-shock protein 90; C9, complement 9; PDIA3, protein disulfide isomerase A3; ANXA2, annexin 2; serum amyloid P-component, APCS

on the information contained in the Ingenuity Pathways Knowledge database.

\section{Statistical analysis}

The results are expressed as mean with standard deviation (SD) unless otherwise stated. Continuous variables were analyzed by using Student's t-test, semi-continuous variables using Mann-Whitney U-test and Fisher's exact test for categorical variables. Analyses were performed using SPSS for Windows (IBM Corp. Released 2018. IBM SPSS Statistics for Windows, Version 25.0). Correlations were detected with linear regression model in 
Table 2 Up- and down-regulated proteins as determined by 2D-DIGE in calcified valves as compared to control valves

\begin{tabular}{|c|c|c|c|c|c|c|c|c|}
\hline \multirow[b]{2}{*}{ Spot } & \multirow[b]{2}{*}{ Protein } & \multirow[b]{2}{*}{ UniProt } & \multirow[b]{2}{*}{ Description } & \multicolumn{2}{|c|}{$\begin{array}{l}\text { Comparison Control vs. } \\
\text { calcified valves }^{\mathrm{a}}\end{array}$} & \multirow[b]{2}{*}{ Theoretical pl/MW (kDa) ${ }^{\mathrm{b}}$} & \multicolumn{2}{|c|}{ Protein identification $^{c}$} \\
\hline & & & & Ratio & P-value & & $\begin{array}{l}\text { Score } \\
\text { (MS, MSMS) }\end{array}$ & $\begin{array}{l}\text { SC (P) } \\
\text { (MS, MSMS) }\end{array}$ \\
\hline \multirow[t]{3}{*}{1} & $\mathrm{HSP} 90 \mathrm{a} / \beta$ & P07900/ P08238 & Heat shock protein HSP90AA1/AB1 & -2.05 & 0.022 & AA1: $1: 4.94 / 84.7$ & 113.0, - & 39(18),- \\
\hline & & & & & & 2: 5.07/98.2 & & \\
\hline & & & & & & AB1: $4.96 / 83.3$ & & \\
\hline 2 & C9 & P02748 & Complement 9 & 1.74 & 0.014 & $5.43 / 63.2(5.42 / 60.9)$ & $83.2,-$ & $21(14)_{,-}^{-}$ \\
\hline 3 & & & & 1.68 & 0.016 & (C9a: 4.59/27.8) & $88.5,-$ & 18(13),- \\
\hline 4 & & & & 1.55 & 0.018 & (C9b: 8.63/33.2) &,- 72.9 &,$- 5(2)$ \\
\hline 6 & PDIA3 & P30101 & Protein disulfide-isomerase A3 & -3.35 & 0.016 & $5.98 / 56.8(5.61 / 54.3)$ & 162.0,- & $46.8(21),_{-}^{-}$ \\
\hline 8 & ANXA2 & P07355 & Annexin A2 & -2.22 & 0.012 & 1: $7.57 / 38.6(7.56 / 38.5)$ & 71.1,- & $21(5)_{,-}^{-}$ \\
\hline 9 & & & & -2.95 & 0.019 & 2: 8.53/40.4 (8.54/40.3) & $199^{*}$, & 33(13),- \\
\hline 10 & APCS & P02743 & Serum amyloid P-component & 2.26 & 0.014 & $6.10 / 25.4(6.12 / 23.3)$ & $75^{*},-$ & $20(4)_{i^{-}}$ \\
\hline 11 & & & & 1.59 & 0.039 & & $80^{*},-$ & $20(5)_{i^{-}}$ \\
\hline 12 & & & & 1.51 & 0.046 & & $82^{*},-$ & $25(5)_{\mathbf{T}^{-}}$ \\
\hline 13 & TAGLN & Q01995 & Transgelin & 3.45 & 0.032 & 8.87/22.6 (8.88/22.5) & 176.00,- & $76(27)_{,-}^{-}$ \\
\hline 15 & LGALS1 & P09382 & Galectin-1 & -2.19 & 0.012 & $5.30 / 14.7(5.30 / 14.6)$ & $92.4,64.8$ & $57(7), 44(2)$ \\
\hline
\end{tabular}

${ }^{a}$ The ratio represents the change of the mean normalized volumes. Statistical significance is shown with the $\mathrm{t}$-test $(P<0.05)$. Ratio and t-test values of the unidentified spots were as follows: spot $5(-2.60,0.0200)$, spot $7(-2.91,0.0311)$ and spot $14(-2.12,0.0159)$

${ }^{\mathrm{b}}$ The theoretical expected spot position in the gel according to the full or matured (in brackets) protein sequence is shown. If the protein exists in different isoforms, then the specific number of the isoform is likewise indicated

'The protein identification shows the MS and/or MSMS scores based on analysis with the UltrafleXtreme MALDI TOF/TOF instrument or measurements with the VOYAGER-DE ${ }^{T M}$ STR $\left(^{*}\right)$. In addition, the sequence coverage $(S C)$ and number of matched peptides $(P)$ are shown

Graphpad Prism 5. $P<0.05$ was considered statistically significant.

\section{Results}

\section{Proteomic analysis of aortic valve calcification}

The proteomic analysis, based on the minimal DIGE, identified a total of 15 differentially abundant protein spots in stenotic valves as compared to control valves according to the selection criteria (fold change $\geq 1.5$ and $P \leq 0.05)$. A typical $2 \mathrm{D}$ gel representing calcified aortic valve proteins is shown in Fig. 1. Further, mass spectrometry analyses identified seven proteins within 12 spots (Table 2) which had undergone significant upregulation i.e. complement 9, serum amyloid P-component (APCS) and transgelin (1.7-, 2.3- and 3.5-fold, respectively, $P<0.05)$ as well as downregulation of heat shock protein HSP90 ( $\alpha / \beta$; genes HSP90AA1/AB1), protein disulfide isomerase A3 (PDIA3), annexin A2 (ANXA2) and galectin-1 (2.1-, 3.5-, 2.2- and 2.2-fold, respectively, $P<0.05$ ) in stenotic valves (Fig. 1 , Table 2 ).

\section{Confirmation of proteomics results}

Western blot was used to validate the the proteomic results of HSP90, ANXA2 and galectin-1. The candidate proteins were selected based on their unknown role in CAVD. A marked downregulation of HSP90 $\beta$ protein levels was detected in stenotic valves compared to controls (Fig. 2a-b), whereas no change in HSP90 $\alpha$ protein levels was observed (data not shown). Considerable interindividual variability was seen in the levels of ANXA2 protein, since it was highly expressed in only two out of three control samples (Fig. 3c). There was no significant difference in galectin-1 protein levels between stenotic and control levels (Fig. 3a-b).

To test if valvular anatomy impact on our data, we performed an unsupervised clustering analysis (principal component analysis, PCA) on the raw proteomic data (Additional file 1: Figure S1). We hypothesized that if valvular anatomy would affect protein expression profile, bicuspid valves should cluster together and distinctly from tricuspid valves. However, we find no evidence of such clustering and in fact, the clearest distinction emerges between control, and AS.

We correlated HSP90 expression levels both with age and calcification of the valves (expressed as proportion of calcified area in aortic valve cusps to total aortic valve). As shown in Additional file 2: Figure S2A-B, the HSP90 $\beta$ protein levels correlated with age of the patients $(P<0.01)$ and calcification of the valves $(P<0.05)$. In addition, the valvular calcification correlated with the age $(P<0.01)$ (Additional file 2: Figure S2C).

In the immunohistochemical stainings, the localization of HSP90 $\alpha$ and HSP90 $\beta$ was virtually identical (Fig. 2be). VICs in both normal and calcified valves were 

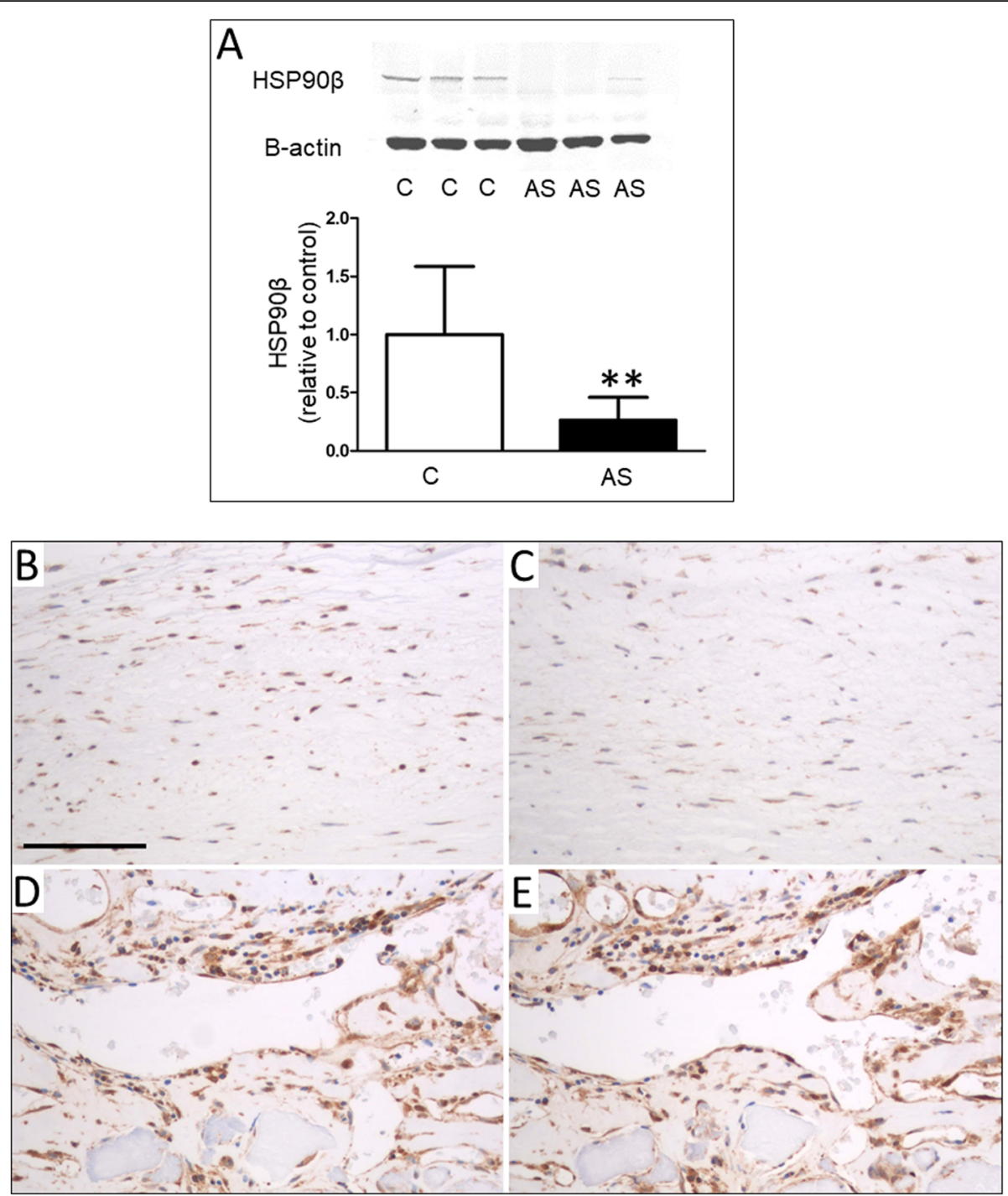

Fig. 2 HSP90 expression in aortic valves. a Western blot analysis revealed decreased HSP90ß protein levels in stenotic valves (AS) when compared to control valves (C). Results are mean $\pm \mathrm{SD},{ }^{* *}=P<0.01$. Representative Western blots are shown. Immunohistochemical stainings against HSP90a (b, d) and HSP90ß (c, e) in aortic valves. VICs in aortic valve displayed cytoplasmic positivity for HSP90a (b) and HSP90ß (c) stainings. Representative examples of adjacent sections of the same area of a control valve. Also the the endothelium was strongly positive for HSP90a (d) and HSP90ß (e). Representative examples of adjacent sections of the same area of neovasculature in calcified valves. There was also a wide positive reaction in valve interstitial cells (VICs) and patchy positivity in inflammatory cells, mainly small lymphocytes. All pictures are at the same scale, scale bar depicts $100 \mu \mathrm{m}$

positive. In addition, the endothelium of neovasculature was widely positively stained, whereas in the surface endothelium, the positive reaction was more patchy. Furthermore, most of the inflammatory cells, mainly lymphocytes, were also positively stained.

\section{Identification of the molecular network between up- and down-regulated proteins}

An IPA-analysis was used to determine the biological relationships among the differentially expressed proteins. The main molecular network exhibiting expression changes based on Fisher's exact test is shown in Fig. 4.
Among the novel putative interactions suggested by IPA, HSP90 was linked to Akt and ERK, and further to p38 MAPK (Fig. 4). Therefore, we conducted Western blot analyses to evaluate the activation of Akt, ERK and p38 MAPK kinases in control and stenotic valves. The ratio of phosphorylated ERK to total ERK was increased (1.5-fold, $P<0.05)$ whereas the ratio of phosphorylated Akt to total Akt was reduced (0.7-fold, $P<0.05)$ suggesting that the Akt and ERK pathways were disturbed in the stenotic valves (Fig. 5a,c). Instead, there was no change in the phosphorylation pattern of p38 MAPK in stenotic valves (Fig. 5b). 


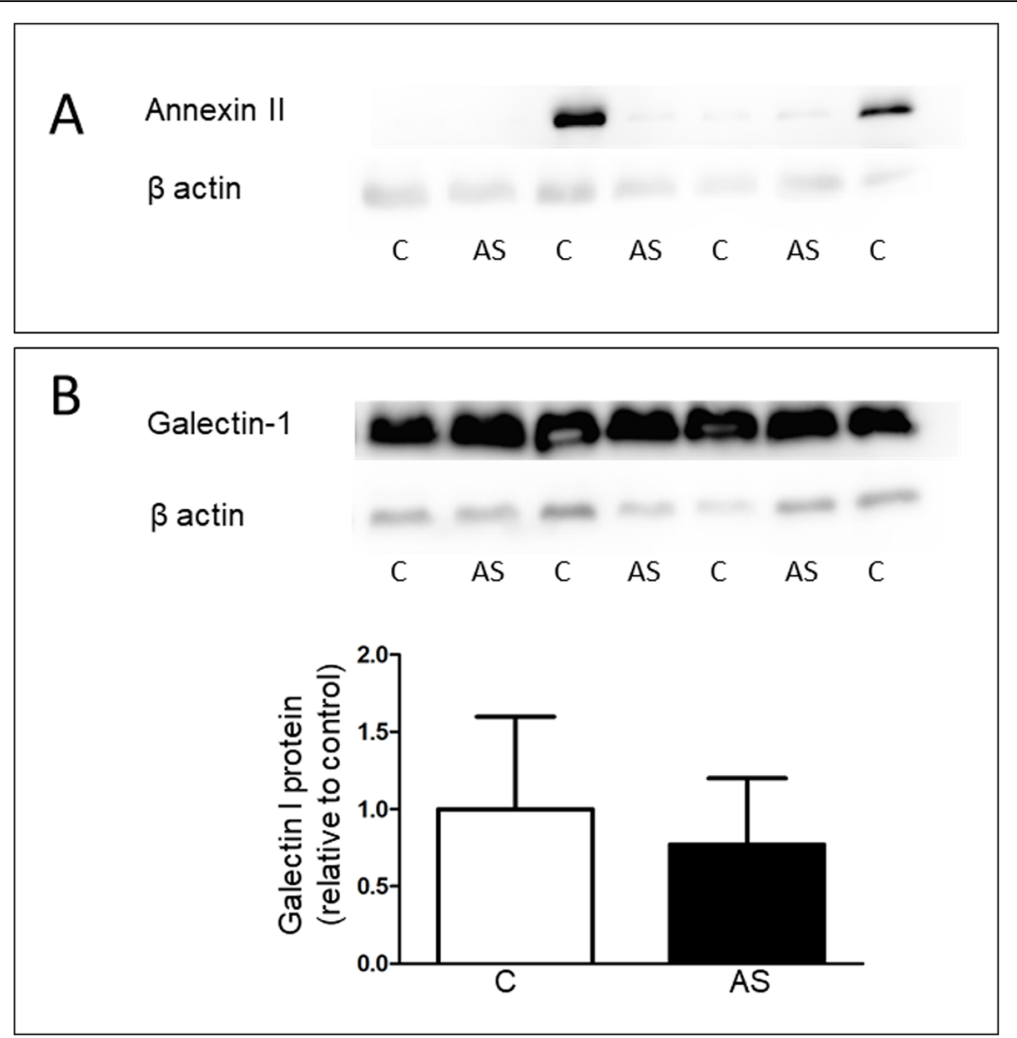

Fig. 3 Protein expression of annexin II and galectin-1 in aortic valves. Western blot analysis showing (a) annexin II and (b) galectin-1 in stenotic (AS) and control valves (C). Representative Western blots are shown. Results are mean \pm SD

\section{Discussion}

Here we describe a 2D-DIGE-determined proteomic profile associated with CAVD. We detected a distinct upregulation of APCS, C9 and transgelin as well as a downregulation of HSP90, PDIA3, ANXA2 and galectin1 proteins in calcified valves in comparison to control valves. We confirmed this decrease in HSP90 $\beta$ protein levels in calcified valves by performing a Western blot analysis and then conducted an IPA analysis to predict HSP90 interactions in CAVD.

This is the first study revealing a decreased expression of HSP90 in calcified aortic valves. HSP90 is a molecular chaperone and a member of a large HSP family. Previously, a decreased expression of HSP27 in calcified valves has been reported in the proteomic study conducted by Martin-Rojas et al. [16]. In addition, several HSP family members are linked to the pathophysiology of atherosclerosis in which they have pro-inflammatory effects and regulate endothelial function (reviewed in [21]). In the endothelium, HSP90 is part of a complex with endothelial nitric oxide synthase ((eNOS)/HSP90) [22-24]. The dissociation of HSP90 causes uncoupling of eNOS, leading to the production of reactive oxygen species (ROS) and endothelial dysfunction [23]. This process might be initiated by pro-inflammatory lipids
[23, 24]. Interestingly, uncoupling of NOS and the increased level of oxidative stress have also been reported in calcified stenotic aortic valves [25]. In our study, HSP90 positivity was seen in the surface endothelium of the valves, and in the endothelium of the neovasculature of the calcified valves. Our findings are similar to those of Martín-Rojas et al. [16], who reported decreased HSP27 protein levels in the endothelium layer of stenotic valves [16]. In summary, the expression of HSP90 in the endothelium supports the idea that HSP90 has a role in regulating endothelial function in the progression of aortic valve calcification.

HSP90 was expressed in inflammatory cells that were mainly lymphocytes. In atherosclerosis, HSP90 is overexpressed in inflammatory sites of human atherosclerotic plaques $[26,27]$. Furthermore, several studies have reported that inhibition of HSP90 can exert atheroprotective effects (decreased plaque size and reduced inflammatory responses) $[27,28]$ and less oxidative stress [29]. In CAVD, the amount of inflammation decreases when the disease progresses and acquires its more calcific phenotype (reviewed in [2]). If the role of HSP90 is related to the propagation of inflammation, it may have a different function in a heavily calcific environment as was present in these stenotic valves. However, 


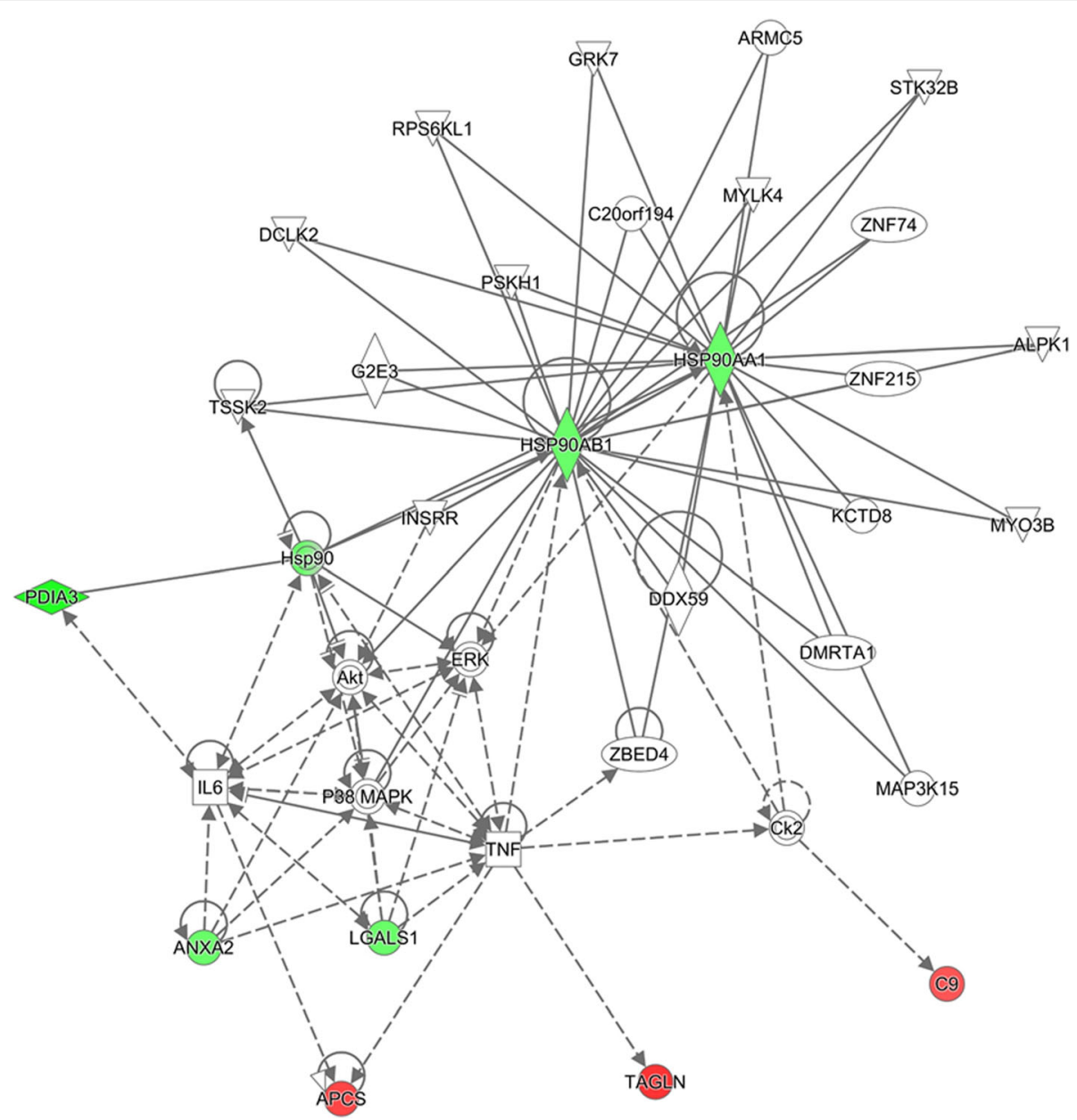

Fig. 4 The molecular network of differentially expressed proteins in CAVD generated by Ingenuity Pathway Analysis. The Ingenuity Pathway Analysis (IPA) Core Analysis-based network displays interactions between proteins that were differentially expressed in stenotic valves as compared to control valves. Up- and down-regulated proteins are in red and green, respectively. Molecules not marked with a color were not altered in the data set but they are possible connections suggested by IPA. Molecules are represented with various shapes that represent the functional class of the gene product. A solid line represents direct interactions and a dashed line represents an indirect interaction. The full names of the molecules are given in Table 3

further studies should focus on HSP90's role in calcific VICs.

HSP90 mediates an ATP-dependent folding of its target proteins that are involved in many diverse cellular processes ranging from intracellular transportation to signal transduction (for general reviews on HSP90 biology, see [30]. The IPA analysis predicted that downregulation of HSP90 would be linked with Akt, p38 MAPK and ERK signalling pathways. We observed an increased activation of ERK1/2 and reduced activation of Aktkinase in calcified valves whereas there was no change in the phosphorylation of p38 MAPK. Previously, Akt and ERK have been shown to mediate leptin induced osteoblast differentiation [31]. In addition, activation of Akt has been demonstrated to regulate calcium deposition [32] and ROS-induced expression of RUNX2 in human VICs [33]. Furthermore, a study with cultured porcine
VICs revealed that ERK inhibition reduced gene expression of myofibroblastic and osteoblastic markers [34]. In our study, Akt and ERK exhibited distinctive phosphorylation patterns suggesting differential regulation of these signalling pathways in the heavily calcified valves.

In agreement with the previous proteomics studies of CAVD [10], [12], [16], we identified increased protein expression of the C9 component of the complement system and APCS. Upregulation of C9 is supported by the data by Helske et al. [35] who were the first investigators to show an activation of the complement system in stenotic valves. APCS, also known as pentraxin-2, is involved in amyloidosis but it is also present in human atherosclerotic lesions [36]. It exerts anti-inflammatory and antifibrotic properties e.g. inhibiting monocyte differentiation into proinflammatory macrophages [37]. APCS has also been implicated in several cardiovascular 
Table 3 Full annotation of genes illustrated in Fig. 4

\begin{tabular}{|c|c|c|c|c|}
\hline Symbol & Entrez Gene Name & Location & Family & Entrez Gene \\
\hline Akt & AKT Serine/Threonine Kinase & Cytoplasm & group & \\
\hline ALPK1 & Alpha kinase 1 & Other & kinase & 80,216 \\
\hline ANXA2 & Annexin A2 & Plasma Membrane & other & 302 \\
\hline APCS & Amyloid P component, serum & Extracellular Space & other & 325 \\
\hline ARMC5 & Armadillo repeat containing 5 & Cytoplasm & other & 79,798 \\
\hline C20orf194 & Chromosome 20 open reading frame 194 & Nucleus & other & 25,943 \\
\hline C9 & Complement C9 & Extracellular Space & other & 735 \\
\hline Ck2 & Casein Kinase II & Cytoplasm & complex & \\
\hline DCLK2 & Doublecortin like kinase 2 & Cytoplasm & kinase & 166,614 \\
\hline DDX59 & DEAD-box helicase 59 & Other & enzyme & 83,479 \\
\hline DMRTA1 & DMRT like family A1 & Nucleus & transcription regulator & 63,951 \\
\hline ERK & Extracellular Signal-Regulated Kinase 1/2 & Other & group & \\
\hline G2E3 & G2/M-phase specific E3 ubiquitin protein ligase & Cytoplasm & enzyme & 55,632 \\
\hline GRK7 & G protein-coupled receptor kinase 7 & Cytoplasm & kinase & 131,890 \\
\hline HSP90 & Heat shock protein 90 & Cytoplasm & group & \\
\hline HSP90AA1 & Heat shock protein 90 alpha family class A member 1 & Cytoplasm & enzyme & 3320 \\
\hline HSP90AB1 & Heat shock protein 90 alpha family class B member 1 & Cytoplasm & enzyme & 3326 \\
\hline IL6 & Interleukin 6 & Extracellular Space & cytokine & 3569 \\
\hline INSRR & Insulin receptor related receptor & Plasma Membrane & kinase & 3645 \\
\hline KCTD8 & Potassium channel tetramerization domain containing 8 & Other & other & 386,617 \\
\hline LGALS1 & Galectin 1 & Extracellular Space & other & 3956 \\
\hline MAP 3 K15 & Mitogen-activated protein kinase kinase kinase 15 & Other & other & 389,840 \\
\hline MYLK4 & Myosin light chain kinase family member 4 & Cytoplasm & kinase & 340,156 \\
\hline MYO3B & Myosin IIIB & Plasma Membrane & kinase & 140,469 \\
\hline P38 MAPK & Mitogen-Activated Protein Kinase P38 Alpha & Cytoplasm & group & 1432 \\
\hline PDIA3 & Protein disulfide isomerase family A member 3 & Cytoplasm & peptidase & 2923 \\
\hline PSKH1 & Protein serine kinase $\mathrm{H} 1$ & Nucleus & kinase & 5681 \\
\hline RPS6KL1 & Ribosomal protein S6 kinase like 1 & Other & kinase & 83,694 \\
\hline STK32B & Serine/threonine kinase 32B & Other & kinase & 55,351 \\
\hline TAGLN & Transgelin & Cytoplasm & other & 6876 \\
\hline TNF & Tumor necrosis factor & Extracellular Space & cytokine & 7124 \\
\hline TSSK2 & Testis specific serine kinase 2 & Cytoplasm & kinase & 23,617 \\
\hline ZBED4 & Zinc finger BED-type containing 4 & Nucleus & transcription regulator & 9889 \\
\hline ZNF215 & Zinc finger protein 215 & Nucleus & transcription regulator & 7762 \\
\hline
\end{tabular}

pathologies (reviewed in [38-40]), and the role of this protein in CAVD should be investigated in detail. Our finding of decreased ANXA2 protein levels in calcified valves confirms the similar proteomic profiling findings of Matsumoto et al. [10]. In addition, ANXA1 and ANXA3 have been previously detected in calcified regions of aortic valves [10, 12]. Furthermore, Cui et al. [41] detected an up-regulation of annexins I, II, III, IV, $\mathrm{V}, \mathrm{VI}, \mathrm{VII}$, and XI in calcifying VIC-derived matrix vesicles, highlighting the significance of the annexins in the calcification process. However, in contrast to a previous proteomic study [16], we observed increased transgelin (SM22) levels in stenotic valves. Since in both studies, transgelin was detected at different positions in the $2 \mathrm{D}$ gel, this discrepancy might be explained by the presence of different transgelin variants.

A major limitation of our work is small number of valves in our proteomic profiling study. This limited sample size raises issue that results do not represent heterogeneity of aortic stenosis patients. This might be the reason why we were not able to confirm with the Western blots the results of the proteomic data on Annexin 

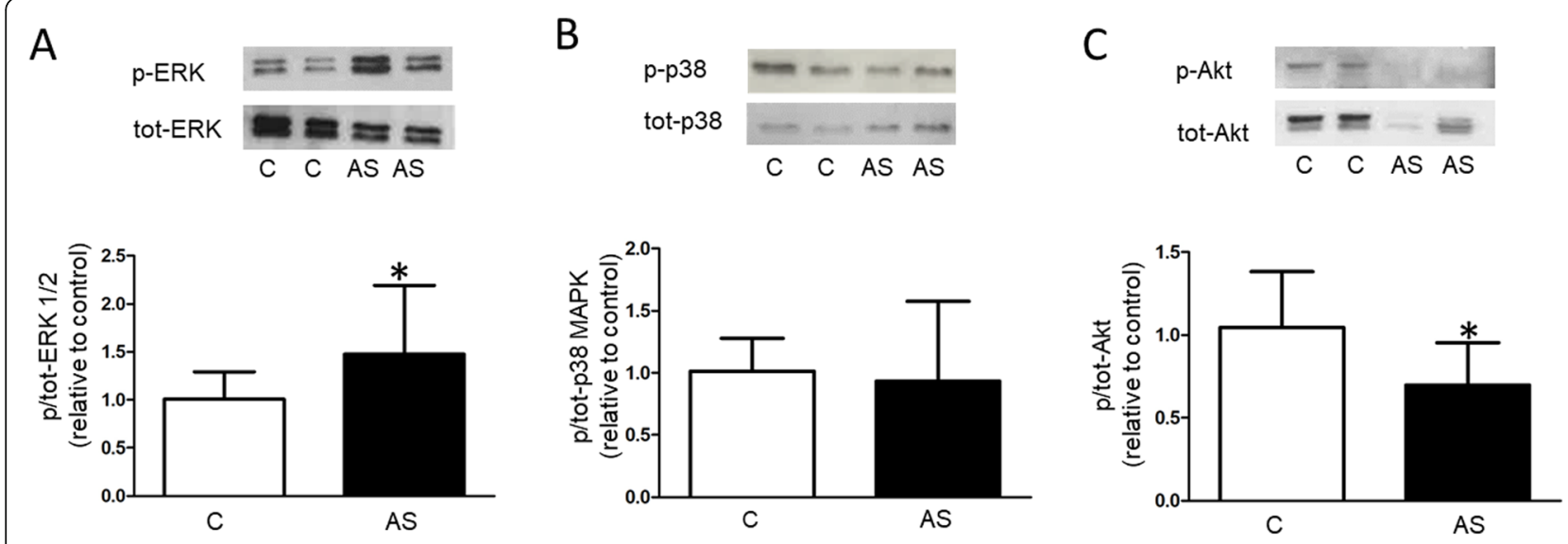

Fig. 5 Phosphorylation of protein kinases in stenotic (AS) and control (C) valves. Western blot analysis of A) Extracellular signal regulated kinase $1 /$ 2 (ERK) 1/2), B) p38 Mitogen activated protein kinase (p38 MAPK) and C) Protein kinase B (Akt). The results in bar graphs are mean \pm SD and expressed as the ratio of the phosphorylated protein kinase to total protein kinase. Representative Western blots are shown. ${ }^{*} P<0.05$

II and galectin-1. Consequently, the generalizability of these results have to be confirmed in larger sample population. However, it is noteworthy that despite limited number patients, we also noticed increased expressions of CP9 component, APCS and ANXA2, in agreement with previous proteomic studies.

In our analysis, HSP90 expression correlated both with age and calcification of the valves. Since aortic valve calcification correlated with age of the patients, these correlations can be explained to be due the fact that aortic valve calcification is most prevalent in the elderly [42]. Thus, we cannot rule out that the changes in HSP90 protein expression are due to the aging and not aortic valve calcification. Furthermore, we did not confirm all the proteomic profiling results with another method. Finally, all the HSP90 associations are only predicted; the experimental validation of HSP90 interaction with Akt and ERK signaling pathways in aortic valve calcification will have to be the subject of some future work.

\section{Conclusion}

Our proteomic analysis identified seven dysregulated proteins in calcified valves when compared to control valves. These proteins may have roles in regulating processes associated with the pathogenesis of CAVD such as the immune response and calcification. Overall, our findings suggest novel insights into the mechanisms of aortic valve calcification and HSP90 may be a central signaling molecule in aortic valve calcification.

\section{Supplementary information}

Supplementary information accompanies this paper at https://doi.org/10. 1186/s12872-019-01294-2.

Additional file 1: Figure S1. An unsupervised clustering analysis (principal component analysis, PCA) on the raw proteomic data was performed to test if valvular anatomy impact on our data. PCA shows the clearest distinction emerges between control, and aortic stenotic group (diseased). Bicuspid valves (1574 and 1575, circulated with red colour) do not cluster together and distinctly from tricuspid valves.

Additional file 2: Figure S2. Correlations between heat-shock protein 90 (HSP90), age of the patients and calcification of the valves. A) HSP90 correlated with the age of the patients (y). Additionally, B) calcium area of the total valve area (\%) correlated with the relative expression of HSP90 C) The age of the patients correlated with calcium area of the total valve area.

\section{Abbreviations}

2D-DIGE: Two-dimensional difference gel electrophoresis; Akt: Protein kinase B; ANXA2: Annexin A2; APCS: Serum amyloid P-component; AS: Aortic stenosis; BMP2: Bone morphogenic protein 2; C9: Complement 9;

CAVD: Calcific aortic valve disease; eNOS: Endothelial nitric oxide synthase; ERK: Extracellular signal regulated kinase; HSP90: Heat shock protein 90; MAPK: Mitogen activated protein kinase; PDIA3: Protein disulfide isomerase A3; ROS: Reactive oxygen species; RUNX2: Runt-related transcription factor 2; VICs: Valve interstitial cells

\section{Acknowledgments}

We thank Dr. Ewen MacDonald for language revision and Dr. Pasi Ohtonen for his help with statistics.

\section{Authors' contributions}

$H R, J W, J R$ and PO designed the study. JW and PO performed the Western blots and analyzed them. JN performed and analyzed the histopathological stainings. SO and UB performed the proteomics analysis. PO interpreted the proteomic analysis data. TP interpreted the patient data. PT did surgical removal of the aortic valves. JR did the molecular network analysis. JW, JR and $\mathrm{PO}$ had major contribution in writing the manuscript. All authors read and approved the final manuscript.

\section{Funding}

This work was supported by grants from the Academy of Finland (Center of Excellence Funding and grants 266661, 276747 and 284504), the Sigrid Jusélius Foundation, the Päivikki and the Sakari Sohlberg Foundation, the Paavo Nurmi Foundation, the Ida Montin Foundation, the Finnish Foundation for Cardiovascular Research, the Emil Aaltonen Foundation, the Aarne Koskelo Foundation and the Orion Research Foundation. None of the funders had role in the design of the study and collection, analysis, and interpretation of data and in writing the manuscript. 


\section{Availability of data and materials}

The dataset supporting the conclusions of this article is included within the article. The raw data used and/or analysed during the current study are available from the corresponding author on reasonable request.

\section{Ethics approval and consent to participate}

This study was approved by the Research Ethics Committee of Oulu University Hospital (decision number 23/2008) and with the 1964 Helsinki declaration and its later amendments or comparable ethical standards. Informed consent was obtained written from all individual participants included in the study.

\section{Consent for publication}

Not applicable.

\section{Competing interests}

TP is currently an employee of MSD Finland.

\section{Author details}

${ }^{1}$ School of Pharmacy, University of Eastern Finland, POB 1627, 70211 Kuopio, Finland. ${ }^{2}$ Research Unit of Biomedicine, Computational Medicine, University of Oulu, Oulu, Finland. ${ }^{3}$ Department of Pathology, Cancer Research and Translational Medicine Research Unit, University of Oulu and Oulu University Hospital, Oulu, Finland. ${ }^{4}$ Proteomics and Mass Spectrometry Core Facilities, Biocenter Oulu, Faculty of Biochemistry and Molecular Medicine, University of Oulu, Oulu, Finland. ${ }^{5}$ Department of Pharmacology and Toxicology, University of Oulu, Oulu, Finland. ${ }^{6}$ Department of Cardiovascular Surgery, Oulu University Hospital, University of Oulu, Oulu, Finland. ${ }^{7}$ Medical Research Center Oulu, Oulu University Hospital and University of Oulu, Oulu, Finland. ${ }^{8}$ Drug Research Program and Division of Pharmacology and Pharmacotherapy, University of Helsinki, Helsinki, Finland.

\section{Received: 18 August 2019 Accepted: 3 December 2019}

\section{Published online: 19 December 2019}

\section{References}

1. Lindman B, Clavel M, Mathieu P, et al. Calcific aortic stenosis. Nat Rev Dis Prim. 2016;2:16006. https://doi.org/10.1038/nrdp.2016.6.

2. Dweck MR, Boon NA, Newby DE. Calcific aortic stenosis: a disease of the valve and the myocardium. J Am Coll Cardiol. 2012;60(19):1854-63.

3. Bosse $Y$, Miqdad A, Fournier D, Pibarot $P$, Mathieu P. Refining molecular pathways leading to calcific aortic valve stenosis by studying gene expression profile of Normal and calcified Stenotic human aortic valves. Circ Genet. 2009:2:489-98.

4. Ohukainen P, Syvaranta S, Napankangas J, Rajamaki K, Taskinen P, Peltonen T, et al. MicroRNA-125b and chemokine CCL4 expression are associated with calcific aortic valve disease. Ann Med. 2015;47(5):423-9.

5. Guauque-Olarte S, Messika-Zeitoun D, Droit A, Lamontagne M, TremblayMarchand J, Lavoie-Charland E, et al. Calcium signaling pathway genes RUNX2 and CACNA1C are associated with calcific aortic valve disease. Circ Genet. 2015;8(6):812-22.

6. Guauque-olarte XS, Droit A, Tremblay-marchand J, Gaudreault N, Kalavrouziotis D, Dagenais F, et al. RNA expression profile of calcified bicuspid, tricuspid, and normal human aortic valves by RNA sequencing. Physiol Genomics. 2016;48:749-61.

7. Coffey S, Williams MJA, Phillips LV, Galvin IF, Bunton RW, Jones GT. Integrated microRNA and messenger RNA analysis in aortic stenosis. Sci Rep. 2016;6(1):36904.

8. Gil-Dones F, Martin-Rojas T, Lopez-Almodovar LF, De La Cuesta F, Darde VM, Alvarez-Llamas G, et al. Valvular Aortic Stenosis: A Proteomic Insight. Clin Med Insights Cardiol. 2010;4:CMC.S3884.

9. Martin-Rojas T, Mourino-Alvarez L, Alonso-Orgaz S, Rosello-Lleti E, Calvo E, Lopez-Almodovar LF, et al. ITRAQ proteomic analysis of extracellular matrix remodeling in aortic valve disease. Sci Rep. 2015;5(1):1-12.

10. Matsumoto K-II, Satoh K, Maniwa T, Araki A, Maruyama R, Oda T. Noticeable decreased expression of Tenascin-X in calcific aortic valves. Connect Tissue Res. 2012;53(6):460-8.

11. Mourino-Alvarez L, lloro I, De La Cuesta F, Azkargorta M, Sastre-Oliva T, Escobes I, et al. MALDI-imaging mass spectrometry: a step forward in the anatomopathological characterization of stenotic aortic valve tissue. Sci Rep. 2016;6:1-12
12. Schlotter F, Halu A, Goto S, Blaser MC, Body SC, Lee LH, et al. Spatiotemporal multi-Omics mapping generates a molecular atlas of the aortic valve and reveals networks driving disease. Circulation. 2018;138(4): 377-93.

13. Kokudo T, Suzuki Y, Yoshimatsu Y, Yamazaki T, Watabe T, Miyazono K. Snail is required for TGFbeta-induced endothelial-mesenchymal transition of embryonic stem cell-derived endothelial cells. J Cell Sci. 2008;121(Pt 20): 3317-24.

14. Suzuki H, Chikada M, Yokoyama MK, Kurokawa MS, Ando T, Furukawa H, et al. Aberrant glycosylation of Lumican in aortic valve stenosis revealed by proteomic analysis. Int Heart J. 2016;57(1):104-11.

15. Trindade F, Ferreira R, Magalhães B, Leite-Moreira A, Falcão-Pires I, Vitorino R. How to use and integrate bioinformatics tools to compare proteomic data from distinct conditions? A tutorial using the pathological similarities between aortic valve stenosis and coronary artery disease as a case-study. J Proteome. 2018;171:37-52.

16. Martín-Rojas T, Gil-Dones F, Lopez-Almodovar LF, Padial LR, Vivanco F, Barderas MG, et al. Proteomic profile of human aortic stenosis: insights into the degenerative process. J Proteome Res. 2012;11(3):1537-50.

17. Pohjolainen V, Mustonen E, Taskinen P, Näpänkangas J, Leskinen $H$, Ohukainen $\mathrm{P}$, et al. Increased thrombospondin-2 in human fibrosclerotic and stenotic aortic valves. Atherosclerosis. 2012;220(1):66-71.

18. Näpänkangas J, Ohtonen $P$, Ohukainen $P$, Weisell J, Väisänen T, Peltonen T, et al. Increased mesenchymal podoplanin expression is associated with calcification in aortic valves. Cardiovasc Pathol. 2019;39:30-7.

19. Ohlmeier S, Mazur W, Salmenkivi K, Myllärniemi M, Bergmann U, Kinnula VL. Proteomic studies on receptor for advanced glycation end product variants in idiopathic pulmonary fibrosis and chronic obstructive pulmonary disease. Proteomics Clin Appl. 2010;4(1):97-105.

20. Rysä J, Tokola H, Ruskoaho H. Mechanical stretch induced transcriptomic profiles in cardiac myocytes. Sci Rep. 2018;8(1):4733.

21. Lu X, Kakkar V. The role of heat shock protein (HSP) in atherosclerosis: pathophysiology and clinical opportunities. Curr Med Chem. 2010;17(10):957-73.

22. Reventun P, Alique M, Cuadrado I, Márquez S, Toro R, Zaragoza C, et al. INOS-derived nitric oxide induces integrin-linked kinase Endocytic lysosomemediated degradation in the vascular endothelium. Arterioscler Thromb Vasc Biol. 2017;37(7):1272-81.

23. Ou Z-J, Chen J, Dai W-P, Liu X, Yang Y-K, Li Y, et al. 25-Hydroxycholesterol impairs endothelial function and vasodilation by uncoupling and inhibiting endothelial nitric oxide synthase. Am J Physiol Metab. 2016;311(4):E781-90.

24. Yan FX, Li HM, Li SX, He SH, Dai WP, Li Y, et al. The oxidized phospholipid POVPC impairs endothelial function and vasodilation via uncoupling endothelial nitric oxide synthase. J Mol Cell Cardiol. 2017;112:40-8.

25. Miller JD, Chu Y, Brooks RM, Richenbacher WE, Peña-Silva R, Heistad DD. Dysregulation of antioxidant mechanisms contributes to increased oxidative stress in calcific aortic Valvular stenosis in humans. J Am Coll Cardiol. 2008; 52(10):843-50.

26. Businaro R, Profumo E, Tagliani A, Buttari B, Leone S, Amati GD, et al. Heatshock protein 90 : A novel autoantigen in human carotid atherosclerosis. Atherosclerosis. 2009;207:74-83.

27. Madrigal-Matute J, López-Franco O, Blanco-colio LM, Muñoz-García B, Ramos-Mozo P, Ortega L, et al. Heat shock protein 90 inhibitors attenuate inflammatory responses in atherosclerosis. Cardiovasc Res. 2010;86(2):330-7.

28. Lazaro I, Oguiza A, Recio C, Lopez-Sanz L, Bernal S, Egido J, et al. Interplay between HSP90 and Nrf2 pathways in diabetes-associated atherosclerosis. Clin Investig Arterioscler. 2017;29(2):51-9.

29. Madrigal-Matute J, Fernandez-Garcia CE, Gomez-Guerrero C, Lopez-Franco O, Muñoz-Garcia B, Egido J, et al. HSP90 inhibition by 17-DMAG attenuates oxidative stress in experimental atherosclerosis. Cardiovasc Res. 2012;95(1): 116-23.

30. Schopf FH, Biebl MM, Buchner J. The HSP90 chaperone machinery. Nat Rev Mol Cell Biol. 2017;18(6):345-60.

31. Rosa M, Paris C, Sottejeau Y, Corseaux D, Robin E, Tagzirt M, et al. Leptin induces osteoblast differentiation of human valvular interstitial cells via the Akt and ERK pathways. Acta Diabetol. 2017;54(6):551-60.

32. Poggio P, Branchetti E, Grau JB, Lai EK, Gorman RC, Gorman JH, et al. Osteopontin-CD44v6 interaction mediates calcium deposition via phosphoakt in valve interstitial cells from patients with noncalcified aortic valve sclerosis. Arterioscler Thromb Vasc Biol. 2014;34(9):2086-94.

33. Branchetti E, Sainger R, Poggio P, Grau JB, Patterson-Fortin J, Bavaria JE, et al. Antioxidant enzymes reduce DNA damage and early activation of 
valvular interstitial cells in aortic valve sclerosis. Arterioscler Thromb Vasc Biol. 2013;33(2):66-74.

34. Gu X, Masters KS. Role of the MAPKJERK pathway in valvular interstitial cell calcification. Am J Physiol Circ Physiol. 2009:296(6):H1748-57.

35. Helske S, Oksjoki R, Lindstedt KA, Lommi J, Turto H, Werkkala K, et al. Complement system is activated in stenotic aortic valves. Atherosclerosis. 2008;196(1):190-200

36. Li XA, Hatanaka K, Ishibashi-Ueda H, Yutani C, Yamamoto A. Characterization of serum amyloid $\mathrm{P}$ component from human aortic atherosclerotic lesions. Arterioscler Thromb Vasc Biol. 1995;15(2):252-7.

37. Moreira AP, Cavassani KA, Hullinger R, Rosada RS, Fong DJ, Murray L, et al. Serum amyloid $P$ attenuates M2 macrophage activation and protects against fungal spore-induced allergic airway disease. J Allergy Clin Immunol. 2010;126(4):712-21 e7.

38. Norata GD, Garlanda C, Catapano AL. The long pentraxin PTX3: a modulator of the immunoinflammatory response in atherosclerosis and cardiovascular diseases. Trends Cardiovasc Med. 2010;20:35-40.

39. Vilahur G, Badimon L. Biological actions of pentraxins. Vasc Pharmacol. 2015; 73:38-44.

40. Xi D, Luo T, Xiong H, Liu J, Lu H, Li M, et al. SAP: structure, function, and its roles in immune-related diseases. Int J Cardiol. 2015;187:20-6.

41. Cui L, Rashdan NA, Zhu D, Milne EM, Ajuh P, Milne G, et al. End stage rena disease-induced hypercalcemia may promote aortic valve calcification via Annexin Vl enrichment of valve interstitial cell derived-matrix vesicles. J Cell Physiol. 2017;232(11):2985-95.

42. Coffey S, Cox B, Williams MJA. The prevalence, incidence, progression, and risks of aortic valve sclerosis: a systematic review and meta-analysis. J Am Coll Cardiol. 2014;63(25):2852-61.

\section{Publisher's Note}

Springer Nature remains neutral with regard to jurisdictional claims in published maps and institutional affiliations.

Ready to submit your research? Choose BMC and benefit from:

- fast, convenient online submission

- thorough peer review by experienced researchers in your field

- rapid publication on acceptance

- support for research data, including large and complex data types

- gold Open Access which fosters wider collaboration and increased citations

- maximum visibility for your research: over $100 \mathrm{M}$ website views per year

At $\mathrm{BMC}$, research is always in progress.

Learn more biomedcentral.com/submissions 